\title{
UM POR TODOS E TODOS POR UM: RELATO DE UM PROJETO DE EXTENSÃO SOBRE PRODUÇÃO DE ESPAÇO URBANO
}

\author{
ONE FOR ALL AND ALL FOR ONE: REPORT OF AN EXTENSION PROJECT ON \\ URBAN SPACE PRODUCTION
}

DOI: $10.23926 /$ RPD.2526-2149.2020.v5.n3.p2051-2068.id883

\section{Cristiana Maria de Oliveira Guimarães Doutora em Ciências humanas: sociologia e política (UFMG) \\ Professora na Instituição IFMG - campus Governador Valadares cristiana.guimaraes@ifmg.ed $\underline{\text { u.br }}$}

\section{Cláudio Alves Pereira}

Mestre em Educação

(UFLA)

Doutorando na Instituição UFES

Técnico em Assuntos

Educacionais na Instituição

IFMG -campus avançado

Arcos

claudio.pereira@ifmg.edu.br
Resumo: $\mathrm{O}$ artigo analisa os resultados de um projeto de extensão realizado com alunos do $6^{\circ}$ ano do ensino fundamental de uma escola municipal em Governador Valadares, Minas Gerais. O projeto tinha como objetivo principal mostrar aos alunos as suas possibilidades de intervir no espaço urbano, partindo da premissa de que esse é produzido histórica e socialmente pelos indivíduos que o constituem. O mote era a produção de um gibi com as aventuras de uma heroína, adolescente como os alunos envolvidos, chamada Garota Reparo, cuja missão seria salvar a cidade dos malfeitos nela realizados. Para isso, foram realizadas oficinas preparatórias e uma intervenção urbana no bairro. Apoiamo-nos nas construções teóricas sobre as utopias do direito à cidade e a educação como práxis transformadora do mundo, colocadas, respectivamente, por Henri Léfèbvre e Paulo Freire. Os resultados mostram a assunção pelos alunos das questões que envolvem o direito à cidade e ao coletivo.

Palavras-chave: Projeto de Extensão. Práxis Transformadora. Produção do Espaço.

Abstract: The article analyzes the results of an extension project carried out with 6th grade elementary school students at a municipal school in Governador Valadares, Minas Gerais. The main objective of the project was to show students their possibilities of intervening in the urban space, based on the premise that it is produced historically and socially by the individuals that constitute it. The idea was the production of a comic book with the adventures of a heroine, a teenager like the students involved, called Garota Reparo, whose mission would be to save the city from the wrongs done in it. For this, preparatory workshops and an urban intervention in the neighborhood were carried out. We rely on theoretical constructions on the utopias of the right to the city and education as worldchanging praxis, put forward, respectively, by Henri Léfèbvre and Paulo Freire. The results show the students' assumption of issues involving the right to the city and to the collective.

Keywords: Extension Project. Transformative Praxis. Production of Space. 


\section{INTRODUÇÃO}

Apresentar a dinâmica urbana, regras, normas, conflitos que interferem na construção cotidiana e contínua de nossas cidades foi o interesse principal do Programa de Extensão Um por todos e todos por um: nosso papel na construção da cidade ${ }^{1}$ aqui apresentado. A sua justificativa foi a ideia de que possibilitar às crianças e adolescentes o despertar de um olhar crítico e atento sobre a cidade é fundamental no caminho para a cidadania. É importante reconhecer que, apesar de ser nosso cotidiano, as questões urbanas não aparecem em disciplinas específicas e tampouco recebem uma atenção especial, motivo de campanhas educativas, como os temas do meio ambiente e da preservação do patrimônio.

Realizado entre abril e novembro de 2018, na Escola Municipal Ivo de Tassis, em Governador Valadares - MG, o projeto foi organizado em três momentos complementares: oficinas preparatórias, a intervenção urbana Brincando de Garota Reparo@ e, por último, a elaboração de histórias para a produção de um gibi, resultado do projeto ${ }^{2}$. O gibi conta as Aventuras da Garota Reparo $\odot$, uma heroína, adolescente, estudante da mesma escola, que salva a cidade das pequenas contravenções nela materializadas. As oficinas preparatórias apresentaram, aos alunos e professores, a partir da ideia do direito à cidade, questões como coletividade, função social da cidade, normas e leis urbanísticas. Entre o final do ciclo de oficinas preparatórias e a elaboração das histórias em quadrinhos, realizou-se a intervenção urbana Brincando de Garota Reparo@, concretizada como uma caminhada por algumas ruas do bairro Turmalina, onde se localiza a Escola Municipal Ivo de Tassis, com o grupo de alunos que conformavam, em 2018, as suas três turmas de sexto ano.

Como se tratava de um projeto de extensão, vale explicar a escolha da escola e do bairro. Entre tantas outras com situação semelhantes, em bairros com características análogas, a Escola Municipal Ivo de Tassis, localizada no bairro Turmalina foi aquela que aderiu à nossa proposta de trabalho, a partir da mediação realizada pela Secretaria Municipal de Educação de Governador Valadares. Esse bairro, por sua vez, é caracterizado por fortes carências urbanas,

\footnotetext{
${ }^{1} \mathrm{O}$ projeto de extensão citado foi realizado no âmbito do IFMG - campus Governador Valadares, em parceria com a Escola Municipal Ivo de Tassis, com fomento financeiro do Edital no 74/2017 da Pró-reitoria de Extensão do IFMG. Objetivava-se uma série de oficinas a professores e alunos do $6^{\circ}$ ano do ensino fundamental, cujo resultado, como explicitado no texto, seria a elaboração de histórias em quadrinhos pelos alunos, para a composição de um gibi As aventuras da Garota Reparo@).

${ }^{2}$ O gibi As aventuras da Garota Reparo@ foi lançado oficialmente em 24 de abril de 2019, em uma cerimônia na Escola Municipal Ivo de Tassis, com os representantes das instituições parceiras e os alunos envolvidos no projeto. Cada um recebeu um exemplar da revistinha em quadrinhos. Confira mais informações em: https://www2.ifmg.edu.br/governadorvaladares/noticias/lancamento-de-gibi-feito-por-alunos-marca- 
marcado pela presença histórica do lixão da cidade e pelos altos índices de violência ${ }^{3}$. Dessa forma, o sentimento de pertencimento é sombreado por um sentido pejorativo e, em boa medida, as questões de identidade dos estudantes com o bairro são bastante conflituosas.

Figura 1 - Bairro Turmalina, Governador Valadares. Vista satélite e mapas

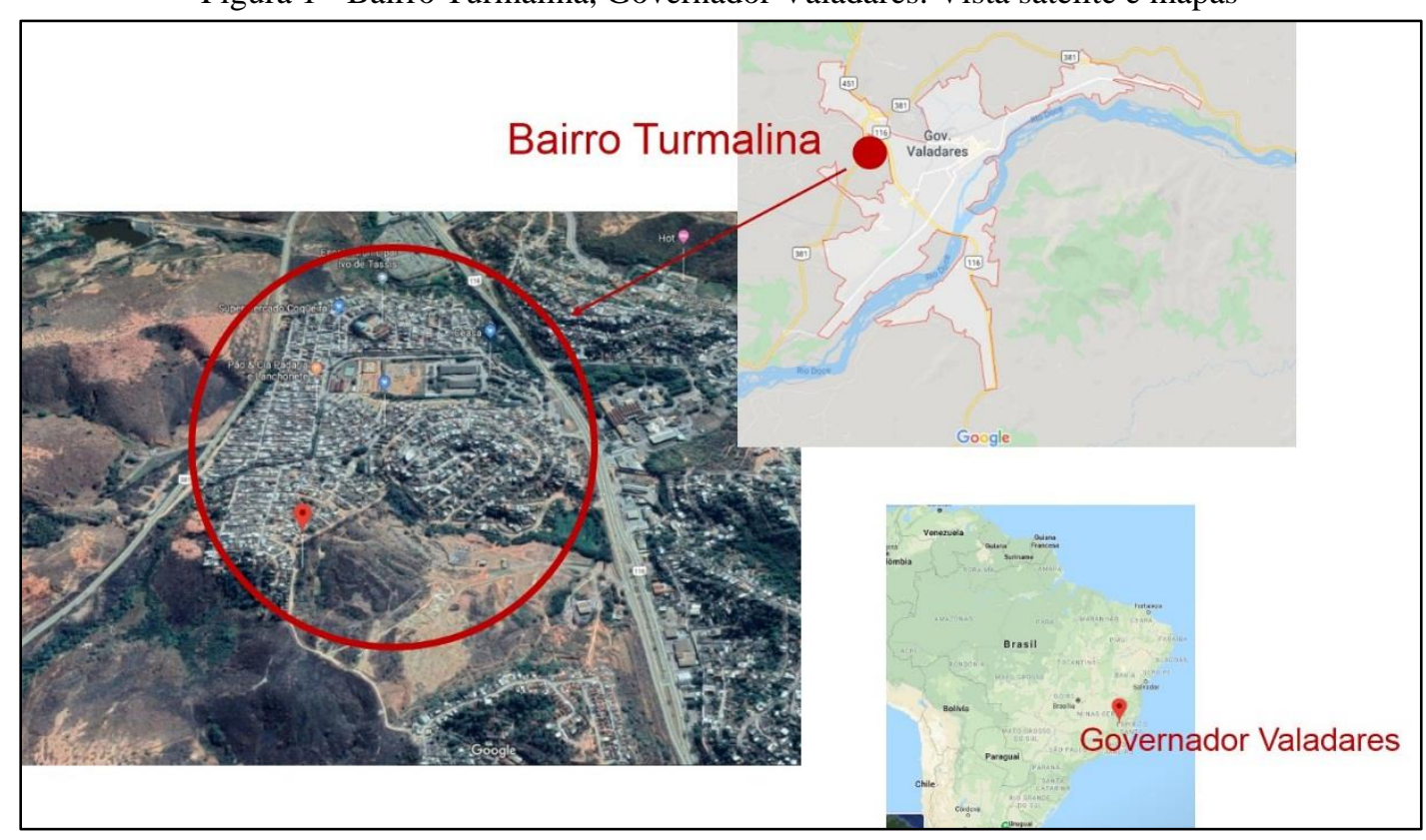

Fonte: Google Maps, em 04 nov. 2019.

\footnotetext{
${ }^{3}$ De acordo com o Relatório final de pesquisa, Grupo 6 - SE 1 - 10 municípios e 2 unidades federadas (UFs).Belo Horizonte, UFMG, 2016 [disponível em: http://fjp.mg.gov.br/index.php/docman/dpp-diretorias-de-politicaspublicas/arquivos-nesp/808-relatorio-senasp-homicidios-final/file ]: “Em Governador Valadares, existe uma clara correspondência entre a disposição de áreas que apresentam maiores indicadores de vulnerabilidade social e a concentração espacial dos crimes de homicídio. Entre os anos de 2012 e 2014, por exemplo, duas regiões se destacaram no município como focos de concentração de mortes violentas: a primeira, na região noroeste, formada pelos bairros Turmalina, Planalto, Altinópolis e Jardim do Trevo; a segunda, na região norte da cidade, abrangendo a região dos bairros Carapina, Nossa Senhora das Graças, Maria Eugênia e Esperança". Para mais, confira GUIMARÃES, C. M. O. Novos valores para o planejamento urbano: o planejamento urbano em Governador Valadares. Tese de Doutorado, UFMG, 2009 e SANTOS, W. F. O território do crime em Governador Valadares: diagnóstico e perspectivas. Dissertação de Mestrado, UNIVALE, 2012.
} 
Figura 2 - Bairro Turmalina, Governador Valadares. Panorâmica

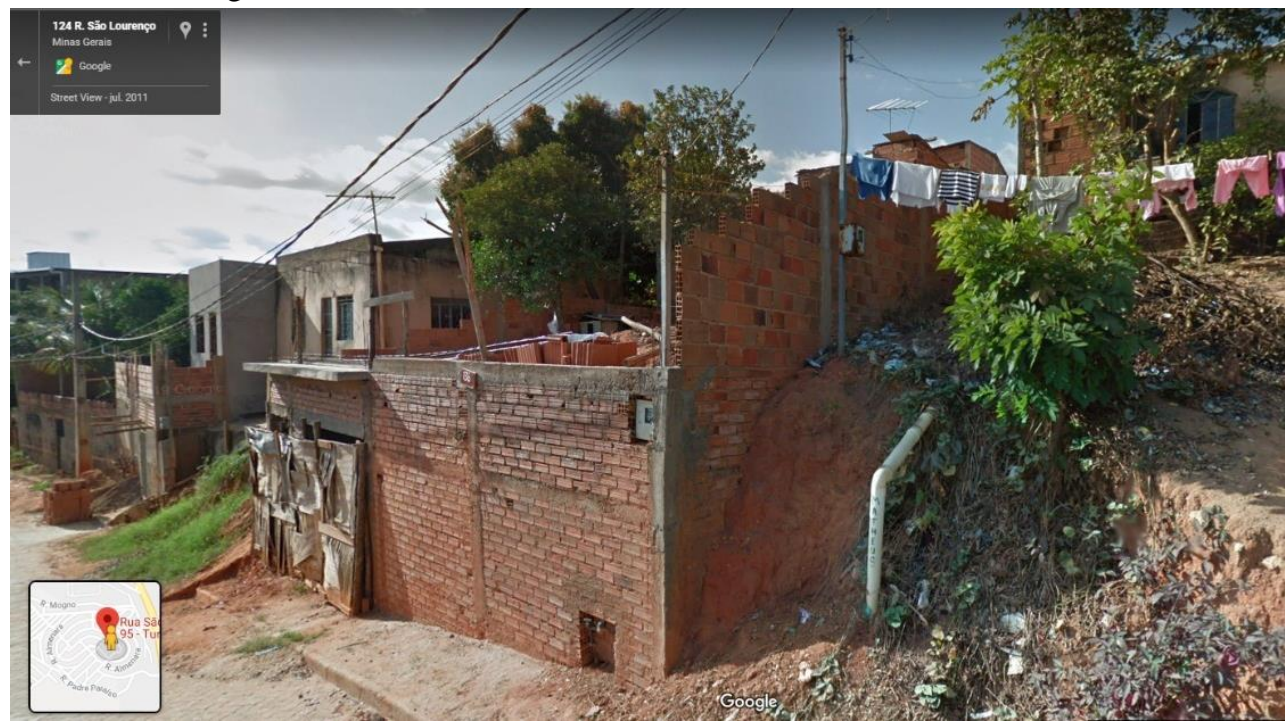

Fonte: Google Maps, nov. 2019.

Sabe-se que a transformação da nossa realidade desigual apenas acontecerá se decididas essas transformações na própria sociedade e a partir de um processo de mudanças estruturais, complexo e compartilhado. No momento, contudo, como um ponto de utopia, é possível pensar na busca pelo direito à cidade, tal como colocado por Léfèbvre $(s / d)$ como um ideal - no sentido estrito da palavra - que inspira o percurso de construção da cidadania. Para isso, é fundamental a desnaturalização dos processos que fazem a cidade, ou seja, a compreensão de que essa é resultado - sempre incompleto - da sua materialidade e das relações que a habitam. $\mathrm{O}$ reconhecimento de que o espaço é tanto produtor como produto das relações sociais (LÉFÈBVRE, $s / d$ ), impõe e expõe a historicidade do processo de sua realização, possibilitando assim, a compreensão das desigualdades nas nossas relações sociais a partir da percepção crítica desse mesmo espaço. Em sequência, coloca como possível, já que produzido pelo homem em sociedade e ao longo da história, sua transformação.

Infelizmente, a restrição dessas reflexões aos círculos acadêmicos e profissionais, dificulta a assunção de um posicionamento crítico por um número maior de pessoas. $\mathrm{O}$ problema não é assumido como próprio a cada um, a exemplo do que acontece em outras agendas como a discussão de gênero, o movimento LGBTQI+, a preservação ambiental e do patrimônio cultural, entre outras. A dinâmica urbana reconhecida - falsamente - como natural, transforma esse processo em algo intangível, não passível de modificação por nós, homens e mulheres comuns. Faz-se necessário, em busca da sua transformação, uma outra leitura do urbano, que desnaturalize suas discrepâncias. 
Como analogia, peguemos o movimento feminista. Ao longo do tempo, suas realizações e conquistas se fazem sobre a desconstrução da naturalização do machismo, reconhecido, portanto, como machismo estrutural. Embora de forma lenta, há o crescimento de uma problematização sobre essa questão e seu reconhecimento como um constructo, histórico e social. O desvelamento de regras ocultas de relações de poder e submissão vem construindo outras percepções dessa realidade, antes tida como natural, que por sua vez, são potencialmente transformadoras.

Proporcionar movimento similar - reconhecidamente, pelos limites do trabalho, em outra ordem de abrangência - voltado à cidade e ao espaço foi o interesse do projeto de extensão aqui em tela. $\mathrm{O}$ argumento defendido é a necessidade de que a lógica dos processos espaciais, seus conflitos e contradições sejam explicitados e conhecidos por todos, para que a partir disso possam ser questionados e modificados quando - e se - possível. Em seu desenvolvimento, recorremos às ideias de Paulo Freire $(2013 ; 2016)$, como uma das bases da sustentação teórica deste trabalho, tal como resumidas nas palavras de AGUIAR (2005):

O pensamento pedagógico freiriano denuncia uma ordem social injusta em que alguns sujeitos assumem o papel de opressores e outros o de oprimidos e propõe uma prática educativa que vise a conscientização e a transformação social, através do desvelamento do mundo, ou seja, através da desnaturalização das práticas de dominação (AGUIAR, 2005, p. 3)

A tentativa de trazer as colocações de Freire para a leitura que Léfèbvre traz do espaço, sua produção, a necessidade de sua análise e posterior questionamento, é o desafio, com todos os riscos aí implicados, exposto na próxima seção.

\section{REFERENCIAL TEÓRICO}

A desnaturalização é uma questão fundamental e complexa dentro dos vários campos das ciências sociais. Tratá-la profundamente não está no escopo deste texto, visto os limites de um artigo. Contudo, suscintamente, faz-se necessário apresentá-la, como justificativa da importância de publicizar, para além dos muros acadêmicos, o processo de produção do espaço, esse que habitamos, como social e histórico, realizado pelos homens organizados em sociedades. Como suporte a esse percurso, traremos um breve resumo da ideia de desnaturalização segundo Netto (2006).

A partir da chamada ordem burguesa, ou em outras palavras, da constituição da sociedade capitalista, são postas as condições que tornam possível aos indivíduos perceberem claramente a fronteira entre natureza e história. Contudo, como ressalta o autor, fala-se em possibilidade, algo que pode ou não se tornar fato, mas que ainda não o é. A ordem burguesa, 
ao mesmo tempo em que põe a possibilidade da percepção do social, enquanto social, em sentido oposto, coloca obstáculos a essa percepção. Não põe óbices naturais, no sentido de uma ligação direta com a natureza, não há nenhum pensador, nesse momento, que considere que nossas instituições são como árvores. Essa naturalização passa por um outro conduto: a desistoricização. Esta desistoricização do social o torna uma matéria gelatinosa e amorfa que é a mesma ao longo de todos os momentos históricos.

Há, assim, um processo de absolutização dos processos que são sociais e históricos. Esses passam a serem compreendidos como atemporais, eternos e naturalmente constituídos, sobre os quais não se pode intervir. Impossibilita-se, desta maneira, a discussão sobre as situações de desigualdades, pois não há a possibilidade da sua problematização.

Neste ponto, encontramos as ideias de Freire $(2013 ; 2016)$ que explicam um dos eixos teóricos da proposição do projeto de extensão Um por todos e todos por um: nosso papel na construção da cidade. $\mathrm{O}$ autor argumenta que uma percepção ingênua da realidade, que associamos ao conceito de naturalização discutido acima, resulta em uma postura fatalista diante da realidade. Em sentido oposto, quando o homem é "capaz de perceber-se, enquanto percebe uma realidade que lhe parecia em si inexorável, é capaz de objetivá-la, descobrindo sua presença criadora e potencialmente transformadora dessa mesma realidade" (FREIRE, 2013, p. 23). Está posta a defesa do processo de desnaturalização como meio para a busca da transformação da realidade, em oposição à naturalização que pressupõe um 'nada a fazer'. Como esclarece Freire (2013), trata-se de uma esperança crítica que move os homens para a transformação.

Em outras palavras, argumenta-se que a obra freiriana é orientada por um fio condutor: a crença na possibilidade de o indivíduo mudar a si e, mudando a si, abre-se a possibilidade de mudar-se o mundo. Seus pressupostos e sua teoria devem ser lidos a partir dessas lentes. Em sua organização de mundo, pensa o opressor em um embate com o oprimido, o qual deve buscar a transformação social. Nesse processo, a educação tem papel fundamental e os pressupostos de sua teoria, fundam-se aí, na formulação de uma pedagogia libertadora, que objetiva uma educação também libertadora, para e com o povo. Essa ideia é apresentada em oposição ao que ele chama de educação bancária.

A maioria dos estudiosos de Freire reconhecem em sua teoria e método, como o oposto de uma fórmula de ensino pautada na transmissão de conhecimento feita de um sujeito a outro, de alguém que detém o saber para outro que não o tem. O educando, compreendido como um homem que faz história, tem a centralidade no processo na obra de Paulo Freire; dessa maneira, 
deve-se partir do saber, do conhecimento trazido por ele de suas múltiplas experiências sociais. Ao educador cabe o papel de fazer a mediação desses saberes, expressos na cultura, na fala e linguagem dos alunos.

Em muitos casos, o educando é reconhecido por Freire como o oprimido. Logo, em última instância, a defesa é sobre os saberes e posição do oprimido no mundo. O homem comum pensa, age e faz cultura enquanto age cotidianamente, logo é capaz de interpretar a realidade e lutar pela sua transformação. Desse pensamento, vem a ideia consequente, de que todos nós somos capazes de ser mais, de dialogar, de produzir conhecimento e ser sujeito na história da qual participa ativamente.

O diálogo, outro vértice da teoria freiriana, ultrapassa a noção de um simples bate papo. Trata-se de uma relação que busca esclarecer o entendimento de duas ou mais pessoas diferentes sobre as coisas, porque são como são; há aqui instaurada a valorização importante do princípio de alteridade e respeito ao outro, ao diferente de mim. Dessa forma, é imprescindível a prática de uma escuta sensível: a questão posta não se resume em dar voz; para ele, o oprimido tem sua voz. Recolocada, a questão passa a ser a predisposição a ouvir, a entender, a dialogar com o outro. Trata-se de um diálogo dialético, contra os mecanicismos; uma relação epistemológica entre um sujeito cognoscente e o objeto cognoscível.

Se de um lado, o trabalho de extensão aqui apresentado pautou-se nos argumentos acima, de outro foi respaldado pelas premissas lefebvrianas, muito já mencionadas, sobre o espaço. Esse, como produto e produtor das relações sociais, é histórico e correspondente ao social de determinado tempo (LÉFÈBVRE, s/d). Importante considerar que o autor, com bastante propriedade, indica que entre a sociedade e seu espaço há descompassos: ideologias se intercalam, grupos diversos disputam a hegemonia e a materialidade do passado sobrevive às transformações em curso. Em outras palavras, o autor está afirmando a existência de descontinuidades e desigualdades presentes no espaço de cada época, que não é, em nenhum sentido, homogêneo. Há nesse processo o envolvimento, não menos importante, dos componentes de conteúdo simbólico. Os monumentos, discursos e narrativas sobre o espaço são, do mesmo modo que a materialidade, constituintes desse.

Léfèbvre (s/d), para explicar a produção do espaço, volta à Marx, ao conceito de produção e a importância das relações de produção como fio condutor do processo analítico sobre a realidade. Relaciona a necessidade de retomar a metodologia marxiana na análise da realidade e do espaço, em substituição às análises dos objetos em si, prática, segundo ele, equivocadamente realizada. Os objetos vistos como absolutos, dissimulam sua origem e 
“tornam-se mais real que o real" (LÉFÈBVRE, s/d). Vale dizer que por real, ele supõe a atividade produtora e suas relações. Mais uma vez, trazendo Marx para a argumentação, ele diz

Tirar a máscara das coisas para revelar as relações (sociais), eis a força de Marx (...) e ninguém deve duvidar dessa análise fundamental, a constatação das coisas, seja de tal objeto, seja do objeto em geral, negligencia isto que as "coisas contem": as relações sociais e as formas dessas relações. (LÉFÈBVRE, 2006, p. 122; 123).

Um exemplo bastante atual e simplificado seria pensarmos em um anúncio publicitário de uma camiseta de grife, que gera desejos e sugere um estilo de vida, mas nem sempre mostra as relações implicadas em sua produção. Essas, são, em alguns casos, relações de exploração. Parece fácil concluir que o conhecimento dessas condições de exploração provocaria outros sentimentos em relação à camiseta de grife, além dos desejos de seu consumo.

Em outras palavras, reencontramos a defesa da desnaturalização do mundo tal como é aparentemente apreendido e a importância da crítica para ultrapassar uma vida alienada e apolítica. Reencontramos, ainda, um ponto de convergência entre nossas leituras (e uso) das ideias colocadas por Léfèbvre e as de Freire.

Essa conclusão se mostra razoável se lembrarmos que os dois autores, cada um a seu modo, buscam inspiração no método e teoria marxiana. Nessa última, é fundamental destacarmos a importância de se construir uma vivência crítica em oposição à alienação, logo, do conhecimento daquilo que sustenta as relações sociais, políticas e econômicas, mas que nem sempre é revelado. A crítica e o desvelamento de processos históricos e sociais permitem potencialmente, ao menos - o agir transformador sobre eles. Seria essa a defesa de Léfèbvre (1999) ao argumentar sobre as possibilidades do direito à cidade que supõe em seu exercício, enquanto um devir possível, um outro cotidiano, baseado em um agir político e não alienado. Em outras palavras, o autor apresenta a possibilidade de uma reação à alienação, à manipulação da vida, pelo exercício da práxis urbana, uma prática teorizada e reflexiva, cotidiana e coletiva. FREIRE (2013), no mesmo sentido, retoma a ideia da práxis - ação e reflexão sobre a realidade - que implica, em sua essência, um conhecimento da realidade. $\mathrm{O}$ autor explica:

Não é possível um compromisso verdadeiro com a realidade e com os homens concretos que nela e com ela estão, se desta realidade se tem uma consciência ingênua. Não é possível um compromisso autêntico se, aquele que se julga comprometido, a realidade se apresenta como algo dado, estático, imutável. (...) Se não a vê e capta como totalidade, cujas partes se encontram em constante interação. Daí sua ação não poder incidir sobre as partes isoladas pensando que assim transforma a realidade, mas [deve incidir] sobre a totalidade. É transformando a totalidade que se transforma as partes e não ao contrário (FREIRE, 2013, p. 5).

Pode-se tecer uma trama única a partir das ideias acima: a aposta no desvelamento do jogo oculto das relações sociais, do que é tido e tomado como natural, como aquilo sobre o qual 
não se pode agir e, logo, modificar. A premissa conhecer-possibilita-transformar poderia ser essa trama, fundamento teórico do projeto realizado.

Passemos agora, ao desenvolvimento do projeto aqui em tela. Lembrando que, tal como os autores, nossas referências, a prática não se diferencia da teoria. Assumimos nessa trajetória a práxis, no sentido posto por Marx, um processo teórico-prático por meio do qual o homem torna-se capaz de superar a investigação teórica e efetivar no mundo projetos conscientes, do que resulta ser ela também uma ação. Assim entendida por Marx, a práxis tem primazia em relação à teoria na superação das contradições e dos problemas que a vida social e os sistemas de sua produção e reprodução apresentam ao homem (MARTINS, 2011).

\section{A REAlização do PROJETO UM POR TODOS E TODOS POR UM: NOSSO PAPEL NA CONSTRUÇÃO DA CIDADE}

Um dos resultados previstos para o projeto era a realização de um gibi com as histórias da Garota Reparo@, uma heroína adolescente cuja missão seria salvar as cidades dos usos e feitos indesejados. A alegria, ao final desse, foi constatar que para além das aventuras escritas com zelo e responsabilidade, o projeto foi exitoso em auxiliar aqueles pré-adolescentes em uma reconciliação com o local onde viviam. Ultrapassando os estereótipos ruins que envolvem o bairro Turmalina, as histórias demonstraram relações de pertencimento, cuidado e afetividade em relação a ele. Entre um quadrinho e outro no gibi, ficou evidente o otimismo de que mudanças eram possíveis e que uma porção dessa reescrita dependeria de cada um dos envolvidos. Para isso, contudo, foi necessário todo um processo, exposto, resumidamente, a seguir.

O projeto de extensão Um por todos e todos por um: nosso papel na construção da cidade, como adiantado, foi desenvolvido em três fases complementares e superpostas: as oficinas preparatórias, a intervenção urbana Brincando de Garota Reparo@ e a elaboração das histórias para a confecção do gibi Aventuras da Garota Reparo@.

As oficinas preparatórias aconteceram na Escola Municipal Ivo de Tassis, semanalmente e em horários pré-estabelecidos, entre maio e outubro de 2018. Foram tratados, como já dito, temas como o direito à cidade, o espaço urbano como coletividade, e de forma simplificada, o processo de produção desse espaço e a disputa entre os diversos atores e o jogo de forças e poderes envolvidos. Em um primeiro momento, as oficinas foram realizadas com os professores; posteriormente, os alunos foram incluídos. Cada oficina tratou um assunto específico, dentre aqueles acima apontados, desde a história da cidade, do bairro Turmalina, 
passando pela abordagem da política urbana na Constituição Federal de 1988, direitos humanos e urbanos até aspectos mais pontuais sobre a legislação urbana, uso e ocupação do espaço, os motivos para cada restrição e seu sentido. O mote de cada uma era a elaboração das historinhas em quadrinhos, afinal, como eles iriam escrever sobre um assunto que não conheciam?! Talvez tenha sido esse o chamariz, para que eles, com pouca idade, tenham se apercebido tão bem da importância das discussões e da sua interferência no cotidiano. Em cada oficina preparatória, eram vários os casos contados pelos alunos, a partir dos pontos levantados, sobre suas rotinas no bairro, notadas agora como um experenciar naquele espaço antes desconsiderado.

A experiência da primeira oficina foi reveladora nesse aspecto. Após a apresentação de todos, foi perguntado sobre o que cada um mais gostava no bairro. Em coro, as respostas foram: “nada”, "aqui é péssimo", completadas por algumas ironias do tipo, "dos bandidos" ou "do que a gente pega no lixão". A seguir, foi exposta aos alunos uma maquete do bairro Turmalina. Nesta, cada aluno deveria localizar sua casa, marcando o local com um alfinete colorido. Essa marcação ficava ali (Figura 3).

Figura 3 - Maquete do bairro Turmalina com a marcação das casas dos alunos

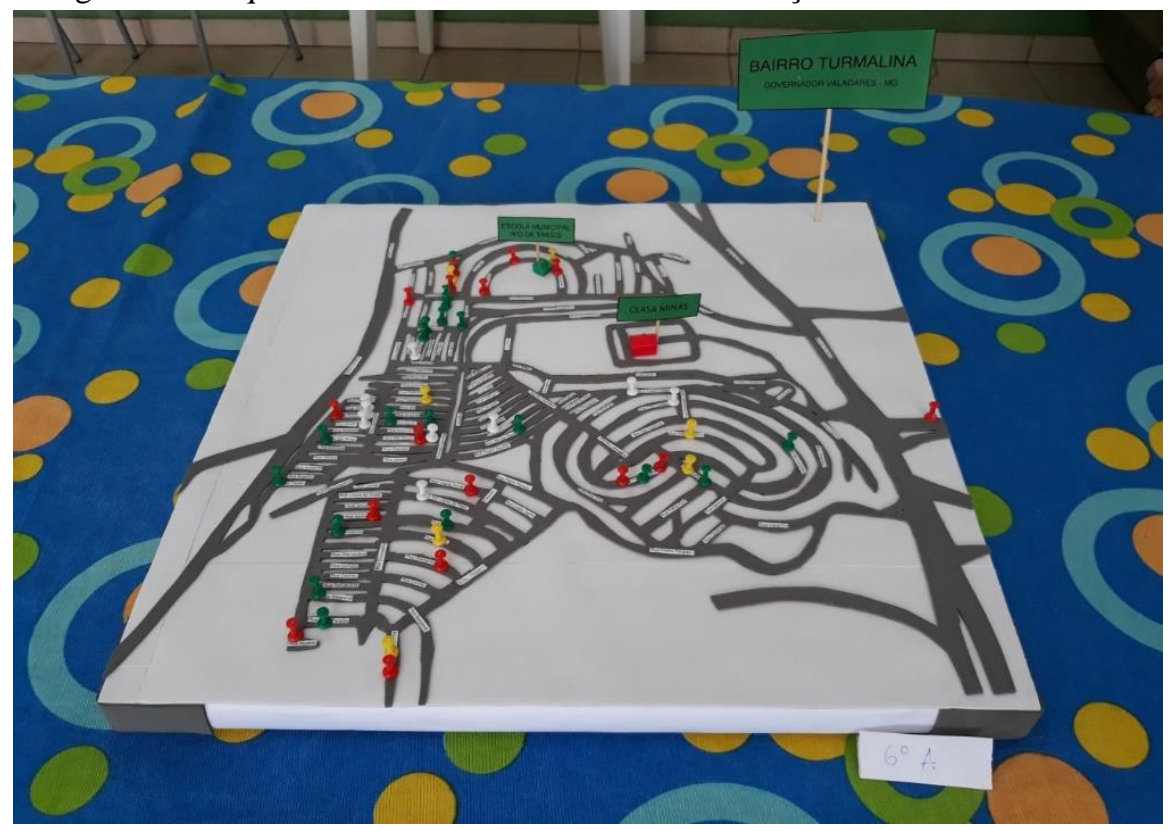

Fonte: Registro da autora em agosto/2018.

Várias foram as relações extraídas desse momento: colegas que moravam próximos e não sabiam; quem morava mais perto e longe da Escola; os caminhos de cada um, a expressão dos locais mais perigosos, agradáveis e desagradáveis do bairro. A partir da materialidade da maquete, o espaço foi sendo apropriado por aqueles pré-adolescentes em divertidos relatos do 
seu dia-a-dia, revelando que as primeiras respostas não contaram de fato sobre as experiências, as relações e o vivido ali no Turmalina, como eles dizem.

Isso se tornou uma constante: em cada oficina, houve a substituição das falas de recusa e desdém do bairro, por expressões amorosas, casos que mostravam vínculos afetivos e lembranças importantes de suas vidas que se mesclavam à materialidade do espaço. A percepção de que as-coisas-de-cada-um-acontecia-ali parece ter evidenciado que havia sim, para além dos rótulos de local violento e de "bairro do lixão", locais significativos para cada um, onde eles se divertiam, cresciam e realizavam suas atividades mais agradáveis, como as aulas de balé ou capoeira, realizadas no Projeto Fica Vivo ${ }^{5}$. O discurso inicial foi se alterando; a consciência dessa mudança revelou que era outra a relação de cada um com o bairro; não era mais aquela de descaso e certa repulsa exposta nas primeiras falas.

Quando chegamos à época da realização da intervenção urbana, o alvoroço entre as turmas era alto, com muitas expectativas e planos sobre o quê e onde gostariam de mostrar e ir. Os esboços das histórias e de algumas ilustrações já estavam também, nessa altura, encaminhados.

Nessa toada, realizamos a esperada intervenção urbana Brincando de Garota Reparo@, concretizada como uma caminhada, nas proximidades da escola, em uma rota pré-definida. No percurso, além de explicações sobre a paisagem, foram identificados pontos que violavam ou confirmavam as ideias debatidas nas oficinas como necessárias para a realização de um espaço melhor para todos. O ponto alto foi a aplicação dos adesivos de 'Aprovado' ou 'Desaprovado' (Figura 4). Eles foram colados de acordo com situações específicas, identificadas pelos estudantes como positividades e negatividades, em relação à possibilidade de exercício do direito à cidade. Exemplificando, são comuns os casos de imóveis onde a garagem vai além dos limites do lote, para que os veículos caibam com mais conforto; também são comuns modificações no desenho e altura das calçadas e níveis da rua para permitir a entrada dos veículos de modo mais fácil, ou mesmo ampliar suas residências ou comércios. São ignorados

\footnotetext{
${ }^{4}$ O lixão foi desativado em 2012. Atualmente, funciona no mesmo local a área de transbordo, para o encaminhamento dos resíduos ao aterro sanitário e, paralelamente, o galpão de separação e preparação para venda dos resíduos recicláveis. Esse último fica a cargo de uma associação da sociedade civil: a Associação dos Catadores de Materiais Recicláveis Natureza Viva - ASCANAVI.

${ }^{5}$ Para mais informações sobre o Projeto Fica Vivo, acesse http://www.institutoelo.org.br/
} 
ou desconhecidos os afastamentos necessários e as regras para as aberturas de iluminação ou ventilação ${ }^{6}$ dessas construções.

Figura 4 - Adesivos com ícone de aprovado, à esquerda, e desaprovado, à direita
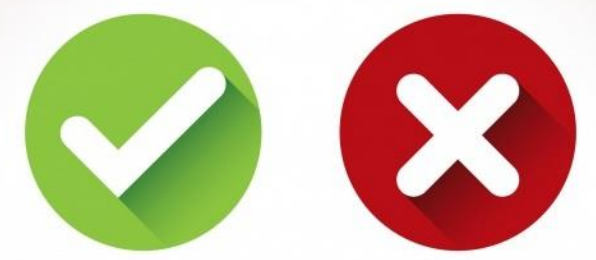

Fonte: Imagem da autora, setembro / 2018.

A postura dos alunos, durante a caminhada, deixou evidente sua compreensão sobre as ideias desenvolvidas nas oficinas - ideia do direito à cidade, espaços compartilhados, meudireito-termina-onde-começa-o-do-outro. Os alunos se mostraram bastante ansiosos para registrar todas as irregularidades referentes às calçadas, lixos depositados inadequadamente e invasões construtivas das vias públicas (Figura 5). Em sentido complementar, era visível a satisfação dos alunos ao encontrar pontos positivos (Figura 6).

Figura 5 - Alunos adesivando a esquina cheia de lixo identificada como uma negatividade à cidade

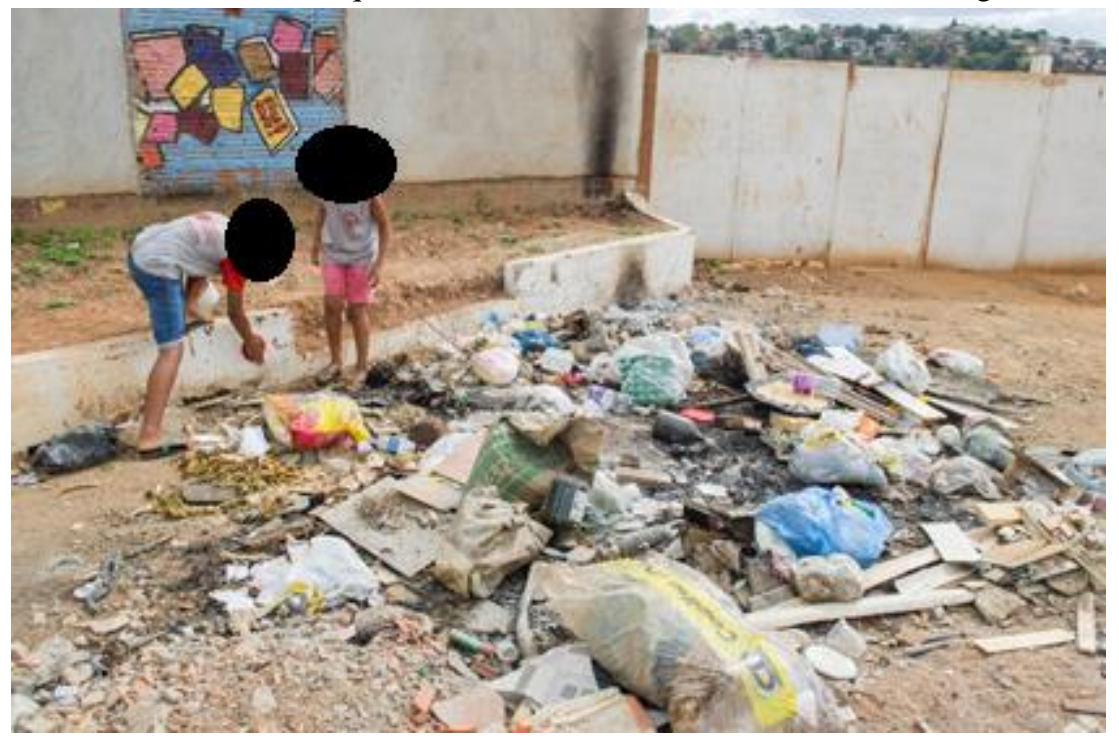

Fonte: Registro fotográfico de Fernanda Silva, outubro/2018.

\footnotetext{
${ }^{6}$ Tomou-se o cuidado, de que os adesivos só fossem colocados em locais públicos, de maneira a evitar constrangimentos às pessoas, moradores dos bairros, que muitas vezes, sem saber ou por acompanhar o que já é costume histórico, em suas práticas construtivas violam o direito à cidade.
} 
Figura 6 - Aluna adesivando a lixeira com o lixo corretamente armazenado. Calçada e gradil em ótima condição. Situação identificada como positividade

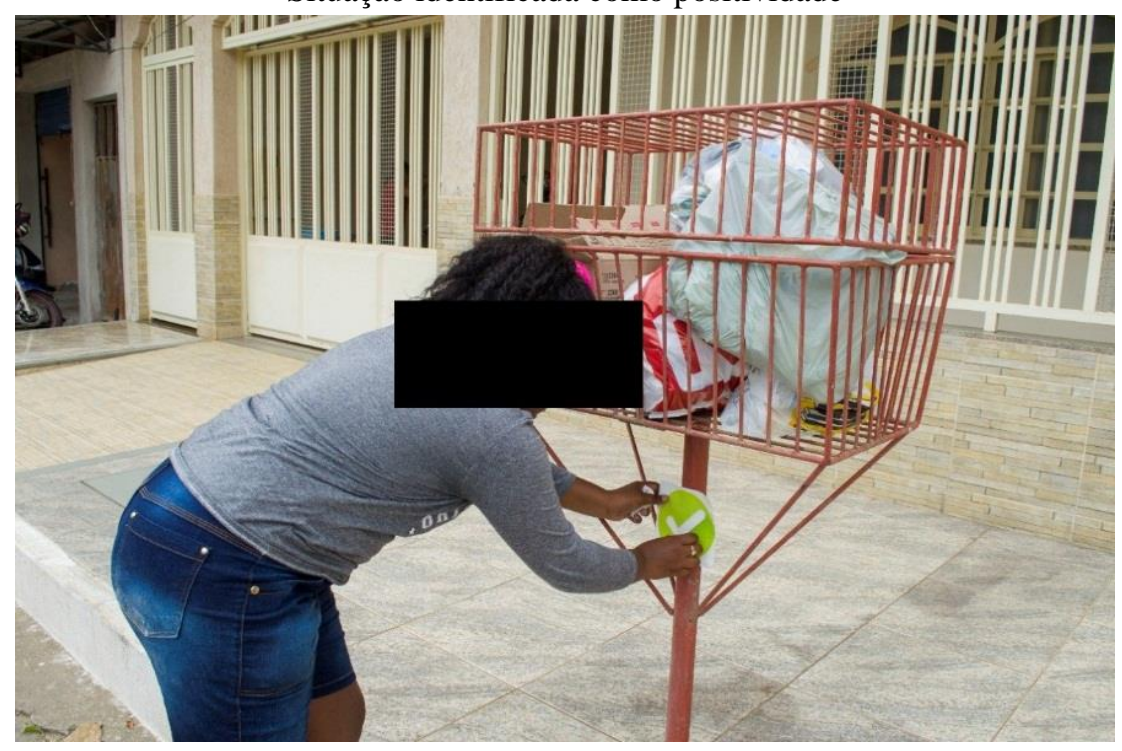

Fonte: Registro fotográfico de Fernanda Silva, outubro/2018.

O processo de elaboração das histórias, que constituem o gibi Aventuras da Garota Reparo ${ }^{\circ}$, como adiantado, percorreu todo o projeto. Ao final de cada oficina, fazíamos em conjunto elucubrações sobre quais aventuras saíram dos assuntos discutidos. Dúvidas sobre a imagem da nossa heroína eram sanadas, os primeiros desenhos apresentados. Em conjunto com os professores de Artes e Língua Portuguesa, as aulas das disciplinas foram utilizadas para o desenvolvimento das ilustrações e da escrita das histórias.

\section{Resultados}

As diferentes histórias (Figura 7) dizem da produção do espaço urbano. Sua leitura mostra a compreensão, pelos participantes, da ideia do espaço como coletivo, da nossa interferência cotidiana na dinâmica do seu uso e dos interesses, muitas vezes conflitantes. 
Figura 7 - Trecho de uma história do gibi As Aventuras da Garota Reparo@, nas mãos da sua autora

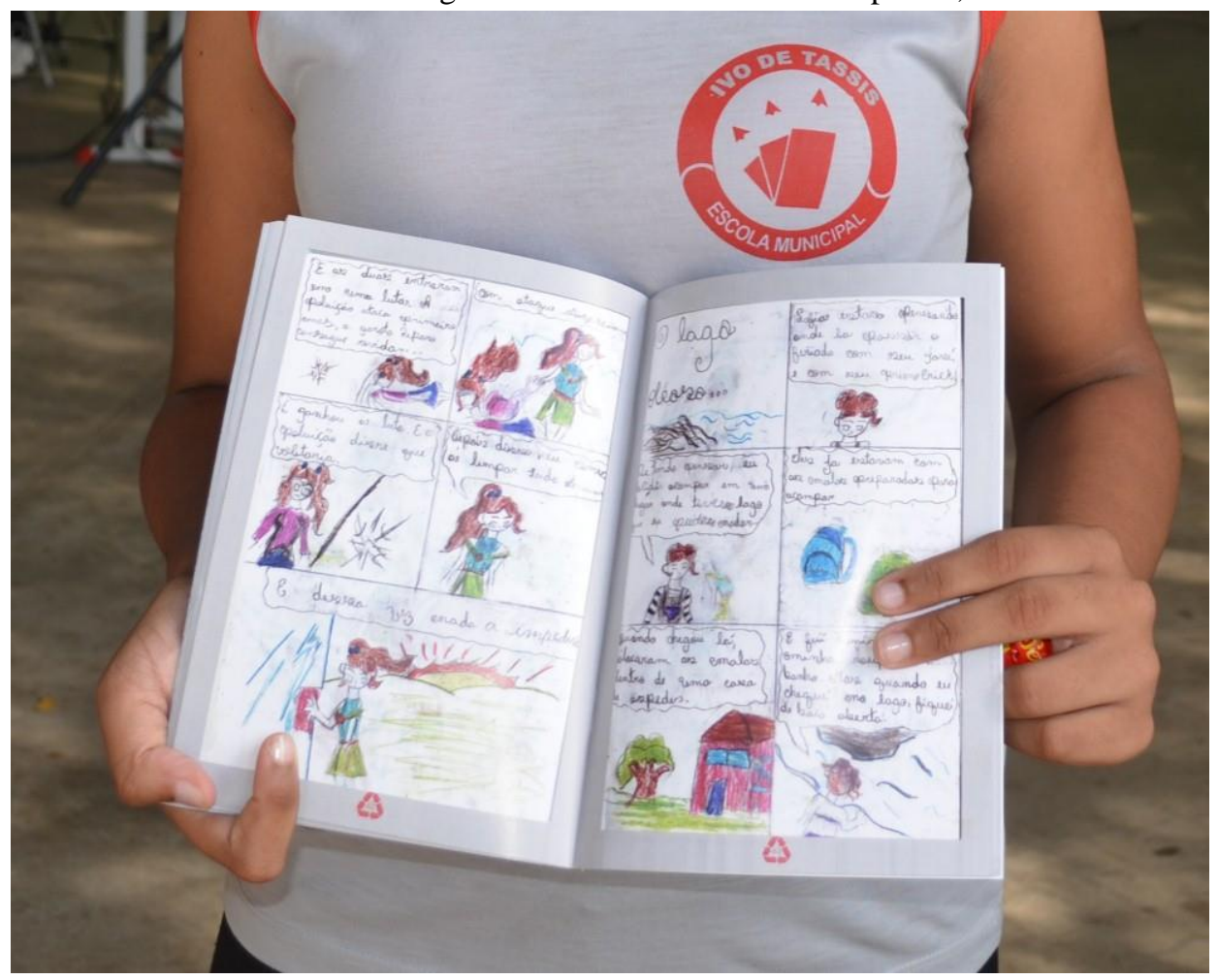

Fonte: Registro fotográfico Fernanda Silva, abril/2019.

Essas ideias aparecem como pano de fundo em cada história que, por sua vez, conta sobre confrontos entre o errado e certo no espaço coletivo, representado, de um lado por alguém que faz a ação indevida e, de outro, a Garota Reparo@ que resolve a situação. No conjunto das aventuras, são recorrentes as vezes em que o tema "carros estacionados na faixa de pedestre" ou "calçadas ocupadas com mesas de bares ou manequins de lojas" aparecem. São apresentados como obstáculos ao direito de ir e vir, principalmente para as pessoas com necessidades especiais. O descarte do lixo nas ruas, calçadas e, de modo proeminente, no rio ${ }^{7}$ é descrito como problema grave e consequência do desconhecimento da população que assim age. Nas histórias em que o tema aparece, sua salvação acontece a partir do esclarecimento de que esse hábito é perverso e traz consequências ruins ao bairro, à cidade e aos seus moradores, com o qual todos concordam. Há uma desnaturalização dos problemas citadinos, exemplificados pelos alunos nos pequenos entraves do dia-a-dia pois, nas histórias, sempre está presente - e com ênfase - quem os causou e, em ato contínuo, a possibilidade de ação sobre a situação indesejada.

\footnotetext{
${ }^{7}$ Governador Valadares é cortada pelo rio Doce, parte indissociável de sua história e paisagem. Em 2015, os rejeitos da mineração, consequência do rompimento da Barragem do Fundão em Mariana (MG), chegaram ao rio Doce, transformando-o em vários aspectos. Dos incalculáveis impactos ambientais, aos prejuízos econômicos, importa aqui, realçar o impacto que a quase perda do rio trouxe à cidade. O sentimento de perda evidenciou que, para além das questões mencionadas, o rio reúne um fundamental valor simbólico e identitário para os valadarenses.
} 
Revela-se a compreensão de que há o produzir do espaço e de sua dinâmica. O espaço não nasce; é produzido. O lixo está nas calçadas, mas não naturalmente, não brotou ali. Alguém foi o responsável por isso. Extrapolando, o lixo permanece ali dias, pois não há o recolhimento adequado, como desejado. Dessas reflexões surgem outras, comentadas nas oficinas realizadas: por que em outros bairros há menos lixo acumulado? Por que nesses últimos, normalmente bairros ricos, o recolhimento do lixo é feito de modo mais regular? Por que o "lixão" fica aqui no Turmalina?

Há a constatação a partir de suas experiências - e de um reconhecer-se em seu mundo de desigualdades, sempre percebidas, mas talvez naturalizadas. Importante pontuar que as observações (sobre as desigualdades) aparecem, agora, contraditoriamente, acompanhadas de um "bem gostar" do bairro. Talvez o que pudesse ser antes simplificadamente resumido como "aqui é horrível; lugar de nada; preciso me mudar para ser alguém" esteja embaraçado com as reflexões de que não precisa ser assim. $\mathrm{O}$ bairro deixa de ser entendido como o problema, petrificado em seus estigmas, com o deslocamento dos questionamentos em direção ao que se faz pelo e com o bairro. Coloca-se na equação, sujeitos, atores que decidem sobre ações realizadas, ou não realizadas, em cada parte da cidade. Vislumbram-se possibilidades de outras práticas, desde que sejam outros os sujeitos atuantes e outros os interesses desses.

A ideia de [da criação de uma] obra tão cara ao pensamento lefebvriano, sobre a qual não poderemos aprofundar, funciona aqui. Obra, para o autor, tem algo de insubstituível e de único, enquanto o produto pode se repetir e resulta de gestos e atos repetitivos. (LÉFÈBVRE, s/d, p. 108).

O exercício crítico do cotidiano, algo realizado pelos alunos, na intervenção e na escrita das histórias, remodelou sua relação com o bairro Turmalina e, a partir disso, o próprio significado deste. Ousamos dizer que houve a criação de outro bairro, mesmo que simbolicamente e num tempo exclusivo, como obra - único, genuíno e original (LÉFÈBVRE, s/d, p. 112). Houve a possibilidade de sua experimentação como festa, sem a apriorística correspondência ao projetado, ao concebido. Pôde-se fazer daquele espaço o seu, apropriar-se dele como uma parte da sua vida, ali e com ele - o espaço - realizada. Dizemos de uma libertação do esquema pré-colocado, para seu uso e vivência no âmbito do percebido e vivido ${ }^{8}$ (LÉFÈBVRE, s/d). Não há, apenas, a utilização de um espaço dado, pronto, projetado, mas sua

\footnotetext{
${ }^{8}$ Sobre a tríade espacial proposta por Léfèbvre confira SCHMID, Christian. A teoria da produção do espaço de Henri Léfèbvre em direção a uma dialética tridimensional. GEOUSP - espaço e tempo, São Paulo, N³2, pp. 89109, 2012. Disponível em:

http://www.revistas.usp.br/geousp/article/view/74284. Acesso em 15 de maio de 2020.
} 
feitura enquanto vivenciado; nesse sentido, reencontramos a criação, não mais a produção em série a partir de um padrão. Temos espaço enquanto obra, não mais um produto comercializável, em que a troca é prioridade sobre o uso.

Para isso foi preciso, como mola propulsora, compreender as condições de seu cotidiano, inclusive as não ditas no discurso e narrativas hegemônicas, para intervir criticamente sobre ele. Contudo, nada é tão simples. Embora Léfèbvre aponte o cotidiano como possibilidade de transformação, ele é, dialeticamente, o âmbito do controle e da regulação pela dita sociedade do consumo dirigido. Como sair dessa encruzilhada? O próprio Léfèbvre nos dá a resposta, aludindo à práxis; segundo ele, a práxis é ato, sempre. Na ação, ela possibilita, constantemente, duas alternativas: a assunção à coação, ao sistema controlado e regulado da hegemonia vigente ou o escape desse.

Percebemos em Freire (2016) o mesmo argumento, embora em outros termos. Em sua obra Pedagogia do Oprimido, ele argumenta

O grande problema está em como poderão os oprimidos que hospedam o opressor em
si participar da elaboração, como seres duplos, inautênticos da pedagogia da
libertação. (...). sua luta se trava em serem eles mesmos ou seres duplos. Entre
expulsarem ou não o opressor dentro de si. Entre se desalienarem ou se manterem
alienados. Entre seguirem prescrições ou terem suas opçães. (...). Entre serem
espectadores ou atores. Entre atuarem a ilusão que atuam, na atuação dos opressores.
(FREIRE, 2016, p.19)

A defesa da práxis, enquanto reflexão e ação dos homens no mundo em busca da sua transformação, sustenta as palavras acima. A saída da situação de expectador para a assunção de outra - de ator, homem sujeito da sua história - é, como também colocado por Léfèbvre, fundamentalmente pela compreensão crítica de sua situação alienada no mundo.

Nos dois autores, a desnaturalização do mundo, reveladora de condições de desigualdade, opressão e alienação descortina a possibilidade da sua transformação. Enquadrase aí nosso otimismo: a participação no projeto possibilitou aos alunos uma ponte para a transformação de cada um em relação a si mesmos, no bairro e no mundo.

\section{CONSIDERAÇÕES FINAIS}

Entendemos, ao final deste, que estar no projeto foi um passo na constituição de um ciclo positivo. No momento da intervenção urbana, ao colarem os adesivos em pontos escolhidos, atuaram e modificaram, mesmo que simbolicamente, a realidade daquele espaço. Vale, neste ponto, pensarmos os adesivos como os grafites, pichações ou os mais recentes stickers, como uma reação às realidades das cidades. Em analogia, em nosso caso específico, o objetivo foi manifestar o estranhamento em relação a realidade ali constatada. Metaforicamente, 
os meninos e meninas, naquele momento, tal como a Garota Reparo@, salvaram o bairro de interferências e práticas indesejáveis (Figura 8).

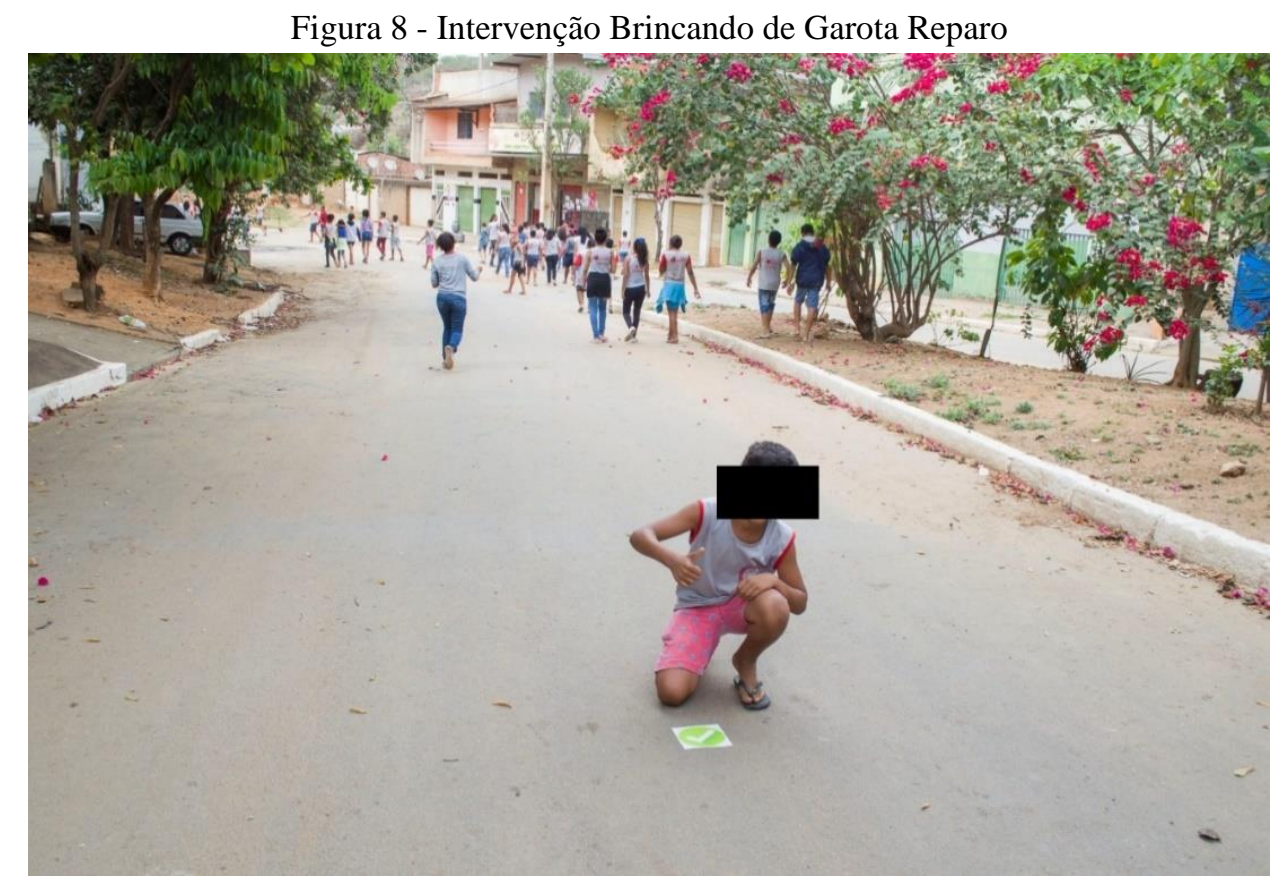

Fonte: Registro fotográfico Fernanda Silva, outubro/2018.

Nas aventuras por eles inventadas e registradas nos gibis, a partir de suas próprias experiências, mais uma vez, os alunos foram os heróis e heroínas do Turmalina. Suas ideias, expressas naquelas páginas, ganharam importância e visibilidade, assim como eles próprios.

\section{REFERÊNCIAS}

AGUIAR. Marta da Silva. Discurso, educação e transformação social. Revista Estudos em Educação e Linguagem, v. 2, n. 2. 2005.

FREIRE, Paulo. A pedagogia do oprimido. $60^{\text {a }}$ ed. Rio de Janeiro: ed. Paz e Terra, 2016.

FREIRE, Paulo. Educação e mudança [recurso eletrônico]. $1^{\text {a }}$ edição. Rio de Janeiro: ed. Paz e Terra, 2013.

LÉFÈBVRE, Henri. O Direito à Cidade. São Paulo, Centauro, 2006.

LÉFÈBVRE, Henri. A revolução urbana. Belo Horizonte: UFMG, 1999.

LÉFÈBVRE, Henri. A produção do espaço. Trad. Doralice Barros Pereira e Sérgio Martins s/d. (mimeo.)

NETTO, João Paulo. Desnaturalizando o fenômeno psicológico: desafios para uma construção teórica. São Paulo: PUCSP, videoteca, 2006 (21/06/2006). 90 min. Série Conversando sobre Psicologia Sócio-Histórica. 
MARTINS, Marcos Francisco. Práxis e "catarsis" como referências avaliativas das ações educacionais das ong's, dos sindicatos e dos partidos políticos. Avaliação, Campinas; Sorocaba, SP, v. 16, n. 3, p. 533-558, nov. 2011.

Recebido em: 18 de agosto de 2020.

Aprovado em: 23 de dezembro 2020. 